Martina Bürger Lazar*, Kaja Pavlin, Nika Bolle

Outpatient rehabilitation service, University Rehabilitation Institute,

Republic of Slovenia, Linhartova 51, 1000 Ljubljana, Slovenia.

Univerzitetni rehabilitacijski inštitut Republike Slovenije - Soča

\title{
Background
}

Chronic pain with moderate to severe intensity affects around $20 \%$ of the general population. Patients and healthcare providers still commonly think of pain as a symptom caused mainly by tissue injury. Historically, pain without an obvious proof of anatomical or neurophysiological origin was labeled as psychopathological. People experiencing chronic pain develop a set of beliefs about the cause of their pain, meaning, and appropriate treatment of their pain (1). Beliefs and views about chronic pain can lead to negative or positive emotional states and (mal)adaptive behaviours.

Pain self-efficacy is an excellent predictor of physical and mental pain-related outcomes and can act indirectly in the relationship between organic ('biomedical') beliefs about pain and disability, anxiety and depression (2).

\section{Objectives and method}

At our Outpatient rehabilitation service, where we offer an interdisciplinary program for chronic pain treatment, we conducted seven educationalinteractive workshops for chronic pain patients (between November 2018 and February 2019). Our research included 103 patients (88 female, 15 male).

At the beginning of an each workshop, the psychologist ask them a question: "When you think about chronic pain, what thought or image goes through your mind? « The patients individually and anonymously wrote their answer on a piece of paper. Their answers were then divided into content categories of automatic thoughts and served for the discussion.

\section{Results}

We divided answers of patients with chronic pain into seven content categories. Below we present the content categories, with a description of the content category and a few examples of answers.

\section{Threat: the perception of pain as impending danger or harm.}

Non-acceptance, fear, uncertainty $(\mathrm{N}=27)$

Examples:

(When) will it stop $(\mathrm{N}=20)$

What will this day / night be like $(\mathrm{N}=2)$

It will be difficult to reconcile with this $(\mathrm{N}=1)$

Fear $(\mathrm{N}=1)$

I'm becoming phobic about seeing my GP ( $N=1)$

Can they help me with something other than pills? $(\mathrm{N}=1)$

I hope the state l'm in gets better $(\mathrm{N}=1)$

Feeling misunderstood by others $(\mathrm{N}=8)$

Examples:

I feel misunderstood by others $(\mathrm{N}=4)$

I don't feel accepted in my environment $(\mathrm{N}=1)$

They look at us like we just yammer all the time $(\mathrm{N}=1)$

Psychological pressures $(\mathrm{N}=1)$

Doctors think you can work normally in spite of the pain $(N=1)$

Psycho-social consequences ( $\mathrm{N}=6$ )

Examples:

Will I lose my job / ability to survive or function normally ( $N=4)$

Feeling tired $(\mathrm{N}=1)$

I will not be able to work as I have before;

that's terrible for a lively person like me $(N=1)$

Causes $(\mathrm{N}=10)$

Examples:

Why me? $(\mathrm{N}=4)$

What have I done wrong? $(\mathrm{N}=3)$

Why is it chronic, why doesn't it stop? $(\mathrm{N}=2)$

Difficult life circumstances $(\mathrm{N}=1)$

\section{Conclusion}

Our content categories of automatic thoughts (secondary appraisals) are consistent with the transactional model of stress by Lazarus and Folkman (1984) of three general types of primary appraisals: threat ("Non-acceptance, fear, uncertainty", Feeling misunderstood by others", "Psycho-social consequences", "Causes"), loss ("Resignation, despair") and challenge ("Impact on pain", "Acceptance, hope"). These findings can help the professionals to identify chronic pain patients' views and beliefs, especially negative automatic thoughts about their pain and facilitate more effective coping with chronic pain and chronic pain related challenges.
Harm - Loss: the perception of significant loss related to pain.

"Resignation, despair" ( $\mathrm{N}=51)$

Examples:

I will hurt for the rest of my life $(\mathrm{N}=15)$

I no longer wish to live $(\mathrm{N}=3)$

Constant suffering, helplessness ( $N=21$ )

It will only get worse $(\mathrm{N}=4)$

I feel sick, disabled, depressed, burden to others $(\mathrm{N}=4)$

Oh well ... ( $\mathrm{N}=1)$

Everything hurts $(\mathrm{N}=1)$

Negative thoughts, bad mood $(\mathrm{N}=1)$

An expression for an illness they cannot explain $(\mathrm{N}=1)$

Challenge: the perception of self-efficacy and internal locus of control related to pain.

"Impact on pain" ( $\mathrm{N}=15)$

Examples:

What do I need to do, how can I master it? $(\mathrm{N}=7)$

I need to do something about it myself $(N=4)$

Don't use so many pills $(\mathrm{N}=1)$

I try not to think about it $(\mathrm{N}=1)$

Love yourself $(\mathrm{N}=1)$

I've done enough to make it go away $(\mathrm{N}=1)$

Acceptance, hope $(\mathrm{N}=5)$

Examples:

Accept is as soon as possible ( $\mathrm{N}=1)$

I've reconciled with it and no longer think about it $(\mathrm{N}=1)$

You can live with this illness $(\mathrm{N}=1)$

I have to get used to it and learn how to live with it $(\mathrm{N}=1)$

I will win. I feel there's a light at the end of the "tunnel", that shines just for $m e(N=1)$

\section{References}

[1] Thorn, B. E. Cognitive Therapy for Chronic Pain. $2^{\text {nd }}$ Ed. New York -London: The Guilford Press, 2017.

[2] Baird, A. \& Sheffield, D. The Relationship between Pain Beliefs and Physical and Mental Health Outcome Measures in Chronic Low Back Pain: Direct and Indirect Effects. Healthcare 2016; 4, 58: 1-11. Doi:10.3390/healthcare4030058. 